\title{
What Drives Deforestation and What Stops It? A Meta-Analysis of Spatially Explicit Econometric Studies
}

\section{Kalifi Ferretti-Gallon and Jonah Busch}

\section{Abstract}

We have constructed a comprehensive database of 117 spatially explicit econometric studies of deforestation published in peer-reviewed academic journals from 1996-2013. We present a metaanalysis of what drives deforestation and what stops it, based on the signs and significance of 5909 coefficients in 554 multivariate analyses. We find that forests are more likely to be cleared where economic returns to agriculture and pasture are higher, either due to more favorable climatological and topographic conditions, or due to lower costs of clearing forest and transporting products to market. Timber activity, land tenure security, and community demographics do not show a consistent association with either higher or lower deforestation. Population is consistently associated with greater deforestation, and poverty is consistently associated with lower deforestation, but in both cases endogeneity makes a causal link difficult to infer. Promising approaches for stopping deforestation include reducing the intrusion of road networks into remote forested areas; targeting protected areas to regions where forests face higher threat; tying rural income support to the maintenance of forest resources through payments for ecosystem services; and insulating the forest frontier from the price effects of demand for agricultural commodities.

\section{JEL Codes: Q15,Q23,Q24}

Keywords: Agriculture; climate change; drivers of deforestation; land-use change; land tenure; payment for ecosystem services; protected areas; REDD+; timber; von Thunen. 


\title{
What Drives Deforestation and What Stops It? A Meta-Analysis of Spatially Explicit Econometric Studies
}

\author{
Kalifi Ferretti-Gallon \\ Center for Global Development \\ Jonah Busch \\ Center for Global Development
}

We gratefully acknowledge support from the David and Lucile Packard Foundation, the Woods Hole Research Center, the United States Agency for International Development, The Nature Conservancy, Environmental Defense Fund, and the Norwegian Agency for Development Cooperation. Much of the work on this paper was conducted while the authors were at Conservation International. This paper has benefited from helpful comments from Victoria Fan, David Kaimowitz, and discussions with many colleagues at the Center for Global Development and Conservation International.

CGD is grateful for contributions from the Norwegian Agency for Development Cooperation in support of this work.

Kalifi Ferretti Gallon and Jonah Busch . 2014. "What Drives Deforestation and What Stops It? A Meta-Analysis of Spatially Explicit Econometric Studies." CGD Working Paper 361. Washington, DC: Center for Global Development. http://www.cgdev.org/publication/what-drives-deforestation-and-what-stops-it-metaanalysis-spatially-explicit-econometric

Center for Global Development 2055 L Street NW Fifth Floor Washington, DC 20036

202.416.4000 (f) 202.416 .4050

www.cgdev.org
The Center for Global Development is an independent, nonprofit policy research organization dedicated to reducing global poverty and inequality and to making globalization work for the poor. Use and dissemination of this Working Paper is encouraged; however, reproduced copies may not be used for commercial purposes. Further usage is permitted under the terms of the Creative Commons License.

The views expressed in CGD Working Papers are those of the authors and should not be attributed to the board of directors or funders of the Center for Global Development. 


\section{Contents}

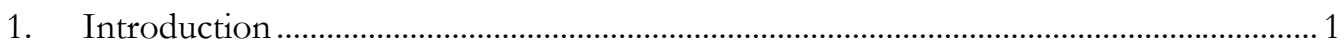

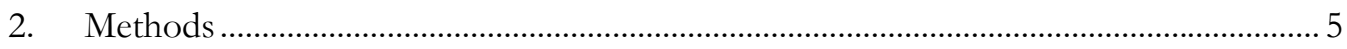

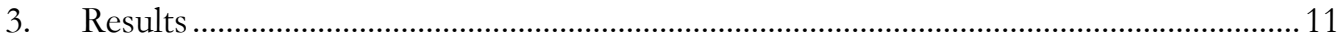

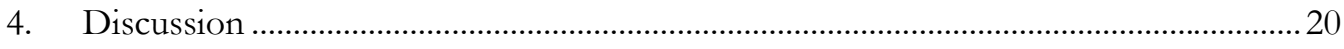

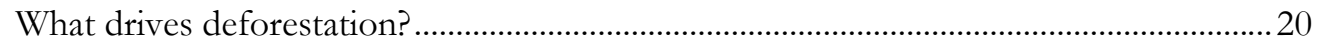

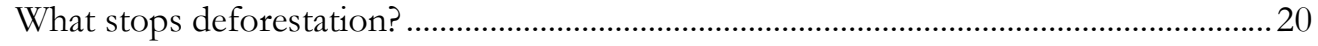

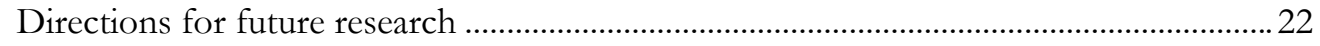

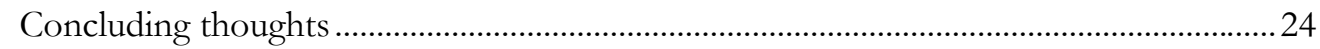

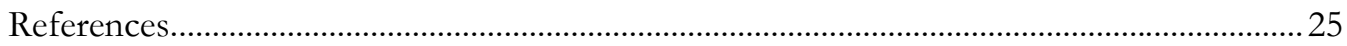




\section{Introduction}

Forests provide a wealth of public services and private goods, including carbon storage, biodiversity habitat, water filtration, storm mitigation, timber and non-timber products, wild foods and medicines, and tourism (Raven 1988; Foley 2005; van der Werf 2009; FAO 2010; Myers et al 2013). Yet despite forests' many values, forested land is being steadily converted to other uses, including cropland, pasture, mining, and urban areas, which can generate greater private economic returns. The rate of net forest loss globally is rapid $(125,000$ square kilometers per year) and increasing (by 2,000 square kilometers per year). Fifty-eight percent of current net forest loss is occurring in the tropics, with another twenty-seven percent occurring in boreal forest (Hansen 2013). Tropical forest is largely being converted to cropland and pasture for the production of soy, beef, palm oil, and timber (Rudel 2009; Hosonuma et al 2012), with the majority of new global agricultural land coming at the expense of tropical forest (Gibbs 2010).

Peoples' decisions to convert land from forest to agriculture, pasture, or mining are influenced by a number of factors, or "drivers." Biophysical characteristics of land such as slope, elevation, wetness, and soil suitability influence the agricultural yields that land can produce. Aspects of the built environment such as roads and towns influence the costs of transporting goods to market. Demand for agricultural and timber commodities, manifested through prices, affect the revenues to be gained from conversion to agriculture or exploitation of forest. Land-use decisions are made by households or communities that vary in their social, economic, cultural and demographic characteristics. And these decisions are made within the context of governance regimes ranging from protected public lands, to open access commons, to leased concessions, to private ownership rights with varying degrees of tenure security. Other authors have categorized drivers of deforestation as proximate or underlying (Geist and Lambin 2002), or as biophysical, social or economic (Chowdhury 2006). 
Public concern over the benefits of forests lost due to deforestation has led to a variety of deliberate policies intended to slow the rate of deforestation. Forested countries have designated protected areas, increased forest law enforcement, and set up programs to pay for ecosystem services. Consumer countries have placed import restrictions on illegal tropical timber. And private supply chain actors have introduced eco-labeling, certification, and sustainable sourcing measures. Three United Nations conventions are actively concerned with tropical deforestation, including the Convention on Biological Diversity (CBD), the Convention to Combat Desertification (UNCCD), and the Framework Convention on Climate Change (UNFCCC). As international concern about climate change has grown, attention has intensified on reducing the 10-15\% of global greenhouse gas emissions resulting from deforestation and forest degradation (REDD+).

All of these efforts benefit from research to understand what factors drive deforestation and what policies can effectively stop it (e.g UNFCCC 2013). This question is especially well suited to spatially explicit econometric analysis, i.e. multivariate regression or matching analyses of the relationship between spatial patterns of deforestation, based on remotely sensed data, and potential driver variables, based on spatially referenced data layers. The number of spatially explicit econometric studies of deforestation has grown rapidly since the publication of the first such study in a peer-reviewed journal in 1996 (Turner et al 1996)

(Figure 1). The goals of these studies have ranged from understanding the determinants of historical deforestation, to anticipating the locations under greatest threat of future deforestation, to comparing quantitative models for analyzing land-use change, to evaluating or designing policies for slowing deforestation. We refer to these studies as "spatially explicit econometric studies" rather than "spatial econometric studies" as the majority of study designs did not account for spatial interactions between observations. Publication of spatially explicit econometric studies of deforestation accelerated with the availability of data on deforestation from the Landsat satellite in 2000 and the increased policy attention on 
REDD+ since 2005. At the same time, Geographic Information Systems and statistical packages to perform econometric analyses have increased in sophistication and decreased in cost. By 2013, 117 spatially explicit econometric studies of drivers of deforestation had been published in peer-reviewed academic journals, spanning disciplines of economics $(n=30)$, geography $(n=22)$, environmental sciences $(n=56)$, policy and management $(n=5)$, and development $(\mathrm{n}=4)$.

However, no systematic and comprehensive review of spatially explicit econometric studies of deforestation has been written until now. In the absence of a meta-analysis it is challenging to distinguish robust relationships from spurious correlations or once-off results, to understand the relative importance of different drivers of deforestation, to reconcile studies' seemingly contradictory findings, or to identify trends across regions or disciplines. Review studies to date have synthesized evidence from across selected spatially explicit econometric studies and non-spatial and non-econometric studies (Angelsen and Kaimowitz 1999; Geist and Lambin 2002; Rudel 2009; Angelsen and Rudel 2013; Pfaff et al 2013), or have focused only on specific policy questions such as the effectiveness of protected areas (Miteva et al 2012), or the effectiveness of payments for ecosystem services (Pattanayak et al 2010; Miteva et al 2012), or the existence of an "Environmental Kuznets curve for deforestation" (Choumert et al 2013).

Here we have compiled a comprehensive database of all spatially explicit econometric studies of deforestation published in peer-reviewed academic journals. We compiled the signs and significances of 5909 coefficients on 1159 uniquely named driver variables from 554 multivariate regressions and matching analyses in 117 studies. We use this comprehensive database to perform a meta-analysis, i.e. a systematic review that synthesizes all empirical evidence that meets pre-specified eligibility criteria to answer a given research question, and that produces overall statistics (Higgins and Green, 2011). We identify driver 
variables for which many studies have consistently found the same direction of influence on deforestation, as well as drivers where the findings of studies do not agree. We identify gaps in the knowledge base where drivers have not been well studied relative to the policy interest in that driver. We compare findings across regions and across disciplines. We provide a consolidated bibliography for the use of future researchers. Drawing upon this meta-analysis we present an overarching theory of what drives deforestation, and we suggest effective policies to stop it.

We address several well-known issues common to meta-analyses. First and most importantly, there is the potential for the selection of original studies in a meta-analysis to have been biased toward areas where findings were expected to be extreme rather than typical, or for the publication process to have been biased toward supporting or rejecting popular theories. If these biases are persistent in the studies in our database, then the findings of our meta-analysis could be biased as well. To examine potential selection bias and publication bias, we compared results where a variable was the focus of a study vs. results from studies where that variable was included only as a control, with the theory that a discrepancy between the two might indicate persistent bias. Second, to address the potential for the meta-analysis to overweight the findings of studies that published more results, we present an analysis that aggregates results from the regression level to the study level. Third, where drivers are exogenous to the land-use decision, as is frequently the case for many biophysical variables, causality can be easily inferred. But in cases when drivers are endogenous, causal inference requires more sophisticated study design involving econometric techniques such as instrumental variables or matching methods. To examine the issue of correlation vs. causation, we compare regression results from studies published in economics journals vs. in other journals, with the assumption that the review process in economics journals is more likely to be tougher on unwarranted claims of causality. 
Even so, there are some important issues that our meta-analysis does not address. The quality of individual studies is not something that we can control for, beyond comparing results by discipline of the journal. Our meta-analysis includes very few studies that span multiple countries, and thus while we can compare the relative influence of driver variables across regions, we can not isolate the effects of specific countries on deforestation. Like its component econometric studies, the meta-analysis only analyzes the relative contribution to deforestation of factors that can be mapped. Some important drivers of deforestation have not been studied using spatial data (e.g. mining; mills and processing facilities; corruption), or have been included in very few studies (e.g. fuelwood collection; off-farm income opportunities). For an in-depth understanding of complex phenomena at individual sites, case study evidence may be superior or complementary to econometric studies.

The remainder of this paper is organized as follows. In Section II we describe the methods we used to compile and analyze our comprehensive database of studies. In Section III we present the results of our analysis. In Section IV we discuss what drives deforestation and what stops it, and suggest important directions for future research.

\section{Methods}

To identify candidate studies for inclusion in our database, we searched ISI Web of Knowledge, Proquest, EBSCO E-Journals Database, and Google Scholar for articles containing combinations of terms related to our subject (e.g. DEFOR*; LAND USE), concept (e.g. CAUS*; DETERMIN*) and methods (e.g. ECONOMETRIC*; REGRESS*) (Table 1). In addition to the keyword search we also identified candidate studies from the literature review sections of included articles. 
We included candidate studies in the database only if they met the following five criteria:

1. The study was published as an article in a peer-reviewed academic journal. We excluded working papers (e.g. Kerr et al 2002), book chapters (e.g. Brown et al 1993), and reports in the grey literature (e.g Lambin 1994). We excluded candidate studies that were published in journals that we could not access electronically $(n=3)$, as well as articles published later than December 31, 2013. Application of this criterion resulted in 223 candidate studies.

2. The dependent variable was a direct indicator of either forest cover or forest cover change. We included both deforestation and reforestation, but excluded indirect indicators of deforestation such as expansion of agricultural land (e.g. Chomitz and Gray 1996). We did not distinguish between natural and plantation forests beyond any definitions applied in the original studies. Application of this criterion eliminated 26 studies, resulting in 197 remaining candidate studies.

3. The indicator of forest cover or forest cover change was remotely sensed and spatially referenced. We excluded studies in which forest cover was determined based on household surveys (e.g. Godoy et al 1998), as well as cross-national studies based on deforestation data that was self-reported by countries to the Forests Resources Assessments of the Food and Agricultural Organization (e.g. Ehrhardt-Martinez 1998). Application of this criterion eliminated 29 studies, resulting in 168 remaining candidate studies.

4. The article presented at least one table of the results of a multivariate econometric analysis. We included both multivariate regression and 
multivariate matching analyses, but excluded univariate regressions (e.g. Burgess et al 2012) and neural networks (e.g. Sangermano 2012). We also excluded results of multivariate matching between two treatment groups, as opposed to between a treated and untreated group (e.g. Gaveau et al 2013). Application of this criterion eliminated 51 studies, resulting in 117 remaining candidate studies.

5. The econometric model of forest cover change included at least one anthropogenic variable. We excluded ecological studies of the natural spatial dynamics of shifting forest edge (e.g. Banfai and Bowman 2007). Because all such studies had already been excluded based on previous criteria, the application of this criterion eliminated no further studies, resulting in 117 studies included in the database.

Our literature search and inclusion criteria resulted in the inclusion of 117 studies in the database (Table 2). These studies included 557 regressions or matching analyses, and 5605 coefficients on 1418 explanatory variables with 1159 unique names. To the best of our knowledge the database has captured this rapidly expanding literature comprehensively. However, the large number of studies in the database implies that our results are likely robust to the possible accidental exclusion of a small number of relevant studies.

For every coefficient on explanatory variable in every results table in every study, we coded the sign and significance of the association of the variable with deforestation as "negative and significant," "not significant," or "positive and significant," at the 95\% confidence level. In cases where the significance of a coefficient appeared to differ between the reported statistical score (e.g. p-value; z-value) and the reporting convention (e.g. ** or bolded text) $(n=20)$, we used the significance as reported by the reporting convention. Where the 
dependent variable was related to forest cover or avoided deforestation rather than to deforestation, we inverted the sign. We did not compile information on point estimates because doing so would require comparing very different metrics within meta-variables (e.g “elevation (m)" vs. "elevation>1500 m"; "rice price" vs. "change in bean price"), as well as comparing the results of different statistical tests. We included squared terms as well $(n=26)$; e.g. U-shaped relationships were coded with one "positive and significant" variable and one "negative and significant" variable.

We categorized the 1159 uniquely named explanatory variables into 40 meta-variables. For example, variables named "Elevation," “Altitude,” and “Above 1500 meters” were all categorized into the meta-variable "Elevation," while variables named "Distance from roads" and "Road density" were all categorized into the meta-variable "Proximity to roads." Within meta-variables, we inverted the coded signs on coefficients as necessary so that all variables were polarized in the same effect direction. For example, within the meta-variable "Proximity to roads," the variable "distance from roads" was inverted while "Road density" was not inverted. We polarized dummy variables in relation to the omitted variable. For example, within the meta-variable "Elevation," the variable "Below 500 meters" was inverted relative to an omitted variable of "Between 500-1500 meters," while the variable "Above 1500 meters" was not inverted. For some meta-variables we were not able to polarize variables easily. For example, within the meta-variable "Soil Class" ( $n=403)$, the variables "Acrisols," "Lithosols," "Gleyic soil" and so forth were beyond our expertise to classify and polarize. Other meta-variables that we were unable to polarize included "Forest Type" ( $\mathrm{n}=58)$, and "Land Use Type" ( $\mathrm{n}=89)$. We excluded these meta-variables from our analysis though not from our database. Additionally, we excluded from our figures though not from our analysis those meta-variables that contained fewer than fifty-five regression results (e.g. "Property size" ( $\mathrm{n}=54)$; “Gender" ( $\mathrm{n}=29)$, "Use of Fuelwood" (n=18); "OffFarm Employment" ( $\mathrm{n}=10)$, and "Erosion" ( $\mathrm{n}=5)$. We excluded interaction terms from the 
analysis $(\mathrm{n}=99)$. Finally, we classified some variables that weren't easily categorized as "Miscellaneous" ( $\mathrm{n}=462)$, and excluded these variables from the analysis as well. For the full categorization of all variables, see the accompanying open-access database.

For each meta-variable, we summed the number of regression outputs or matching outputs that found the association between that meta-variable and deforestation to be negative and significant, not significant, or positive and significant. We then term the meta-variable to be consistently associated with lower (or higher) deforestation if the ratio of positive and significant outputs to negative and significant outputs was statistically significantly less than (or greater than) 1:1 in a two-tailed t-test at the $95 \%$ confidence level. We termed the metavariable to be not consistently associated with lower or higher deforestation if the ratio of positive and significant outputs to negative and significant outputs was not statistically significantly distinguishable from 1:1.

To address potential overweighting within the database of studies that reported more regression results, we performed an analysis in which we aggregated regression-level results to the study level. For each uniquely named variable within a study, the variable was coded at the study level as "negative and significant," "not significant," or "positive and significant" based on the plurality of regression-level codes for that variable within the study. In the case of ties between two regression-level codes, the variable was coded at the study level as "not significant."

To examine potential selection bias and publication bias, we compared results where a variable was the focus of a study vs. results of studies where that variable was included only as a control. We assumed that the second type of study was less likely to be biased by selection issues, though we recognize the possibility that the first type of study might be more careful in its design and thorough in its analytical methods with regard to that variable. A variable was determined to be the focus of a study if the title or abstract of the study 
mentions inquiry into the effect of this variable on deforestation as a motivation for undertaking the study. Findings from generic inquiries into determinants of deforestation were not coded as the focus. For example, an abstract stating that "Many studies conclude that building and upgrading roads increases pressure on forests but some find that new and better roads may reduce the rate of deforestation... we tested whether the existence and size of roads in 1995 affected the level of forest cover in 2000" (Deng et al, 2011) resulted in roads being coded as the focus of the study, while an abstract stating "we assessed the effects of biophysical and anthropogenic predictors on deforestation in Brazilian Amazonia...trends suggest that deforestation is being largely determined by human population density, highways and dry season severity" (Laurance et al, 2002) did not result in these variables being coded as the focus. A study could have more than one variable, or no variables, coded as the focus.

To examine the issue of correlation vs. causation, we compared results from studies published in economics journals vs. in other journals, with the assumption that the peerreview process in economics journals might be tougher on unsubstantiated claims of causality. We assumed that the peer-review process in economics might also be more rigorous regarding other potential biases due to multicollinearity, omitted variables, and so forth. An alternative approach to screening papers by review quality, journal impact factor, was considered but rejected due to observed disparities in citation rates across disciplines. To address the potential overweighting by findings from more commonly studied regions, we disaggregated our results by three major regions_Africa ( $\mathrm{n}=11)$; Asia ( $\mathrm{n}=27)$; and Latin America/Caribbean $(n=70)$. Results from other regions $(n=9)$ were not disaggregated. In addition we disaggregated our findings by regressions in which the dependent variable was forest cover from those in which the dependent variable was forest cover change. 
Our database also compiled information on other variables reported by the included studies, including year of publication, size of study area, data source, data resolution, number of forest cover snapshots, average time interval between snapshots, unit of observation, size of unit of observation, sampling design, number of observations, regression results, variables and coefficients, functional form of regression, coefficient of determination and reported treatment of spatial correlation. These summary statistics are displayed in Table 3.

\section{Results}

Potential drivers of deforestation varied widely in the direction of their relationship with deforestation, the degree of agreement across studies, and the size of the evidence base (Figure 2). Variables related to biophysical characteristics of land (e.g. slope; elevation; wetness; temperature; soil suitability; soil class; erosion; forest type; distance to water) were included in most studies ( $\mathrm{n}=97 / 117)$. These biophysical variables had a clear impact on deforestation. Deforestation was consistently lower at higher elevation (negative and significant: -160 | not significant: 98 | positive and significant: +42), on steeper slopes ($177|151|+60)$, and in wetter areas $(-106|68|+78)$, while deforestation was consistently higher on soil that was more suitable for agriculture $(-26|73|+54)$. Proximity to water ($23|47|+34$ ) was not significantly associated with higher or lower deforestation. Biophysical characteristics influence the deforestation decision through accessibility, clearing costs, and agricultural productivity. Perhaps because biophysical variables are so unambiguously exogenous to the deforestation decision, and the causal pathways influencing deforestation so logical, exploration of biophysical variables was almost never the primary focus of a spatially explicit econometric study. The only exception was Chomitz and Thomas (2003), which explicitly studied wetness, concluding that wetter areas saw less deforestation due to lower agricultural potential rather than lower accessibility. The associations between biophysical variables and deforestation were robust across level of analysis (regression-level vs. study level; Figure 3), focus of study (variable of interest vs. control variable; Figure 4), 
discipline of journal (economics vs. non-economics; Figure 5), and world region (Africa vs. Asia vs. Latin America/Caribbean; Figure 6), with the sole exception of wetness, which was associated with lower deforestation at the regression level $(-106|68|+78)$ but higher deforestation at the study level $(-16|12|+20)$, and lower deforestation in economics journals $(-52|22|+7)$ but higher deforestation in other journals $(-54|46|+71)$. Higher elevation and steeper slope were associated with both lower forest cover and lower rates of deforestation, while associations for all other metavariables were robust to the choice of independent variable (Figure 7).

Variables related to built infrastructure (e.g. proximity to roads; proximity to urban areas) were among the first studied (Nelson and Hellerstein 1997) and the most studied ( $\mathrm{n}=$ 88/117). Roads $(-117|161|+270)$ and urban areas $(-72|195|+170)$ are consistently associated with higher deforestation. Built infrastructure increases deforestation by lowering transportation costs to markets (Cropper 2001), by making frontier land more accessible to new migrants (Mertens and Lambin 2000); and by enabling the transformation of remote economies from local subsistence agriculture to market oriented farming systems. The exogeneity of built infrastructure to the land-use decision is easy to assume for large cities and highways. At fine scale, the expansion of smaller local roads and settlements is likely endogenous to local clearing decisions. At intermediate scales, the expansion of roads and towns may occur as part of simultaneous agricultural rural expansion policy that affects deforestation. Proximity to roads and cities decreases forest cover consistently, but not universally. In contrast to natural forests, proximity to cities has been found to increase the presence of shade-grown coffee in Mexico (Blackman 2008) and El Salvador (Blackman 2012) and green space for urban residents in China (Gong 2013). Getahun (2013) found that regions in Ethiopia that are more integrated with cities are less reliant on clearing for subsistence agriculture as they have more economic alternatives. And while the literature is in agreement that new roads in remote forested areas lead to deforestation, debate has 
persisted as to whether road improvement in regions with substantial prior clearing can attract development away from other regions with more forest remaining. (Pfaff 2007a; Weinhold and Reis 2008; Deng 2011). The associations between built infrastructure variables and deforestation were robust across level of analysis, focus of study, discipline of journal, world region, and dependent variable.

Since most forest land is cleared for agriculture and pasture, it is not surprising that among the nine meta-variables consistently associated with higher deforestation are three related to agriculture (50/117): agricultural activity $(-53|74|+99)$; agricultural prices $(-8|96|+76)$; and proximity to agriculture $(-10|13|+34)$. Pasture activity is associated with higher deforestation as well $(-7|9|+12)$. Deforestation has been found to be higher with higher commodity prices in Indonesia (Gaveau 2009; Wheeler et al 2013) and Brazil (Hargrave and Kis-Katos 2012), and on lands with greater potential agricultural revenue in Costa Rica (Pfaff 2007b) and Indonesia (Busch et al 2012). However, agriculture is not a monolith. Its effects have been found to vary across mechanized agriculture, small-scale agriculture, and cattle ranching in Bolivia (Muller et al 2012). And indeed these different forms of agriculture can have complicated interactions. For example, the encroachment of mechanized agriculture on existing pastures has been found to displace pasture activity to the forest frontier in Brazil (Arima et al 2011). The associations between agricultural variables and deforestation were robust across level of analysis, focus of study, discipline of journal, and world region. More agricultural activity and greater proximity to agriculture were associated with both higher forest cover and higher rates of deforestation.

One might expect timber to show the same consistent association with higher deforestation as agriculture, but in fact a different relationship emerges. Among the five meta-variables not consistently associated with either higher or lower deforestation, three are related to timber: timber prices $(-27|32|+19)$; community forestry $(-37|66|+29)$; and timber activity (- 
$37|20|+40$ ). The mixed relationship between timber variables and deforestation suggests that the economic returns that forests provide through timber harvest may be forestalling more rapid conversion of these forests to agriculture, even while logging activity is often associated with the construction of new roads in remote areas, which can lead to deforestation later. Findings related to timber variables come with several caveats. Satellites used to detect deforestation may not detect all the forest degradation caused by logging. Plantation forests may be directly replacing more-biodiverse and carbon-rich natural forests. Logging, like agriculture, is not monolithic, and logging practices vary in their sustainability as in Ecuador (Lopez 2010). And the relationship between "working forests" and forest cover may be dynamic, with clearing slowing as a forest management association consolidates as in Ethiopia (Takahashi and Todo 2012) or rebounding after relative prices swing in favor of non-forest commodities as in Mexico (Ellis 2010). The associations between timber variables and deforestation are sensitive to a variety of disaggregations. Associations flip signs from the regression level to the study level for timber price (regression level: $-27|32|+19$; study level: $-1|2|+2$ ), timber activity (regression level: $37|20|+40$; study level: $-3|6|+2$ ), and community forestry (regression level: $-37|66|+29$; study level: $-9|19|+11)$. Community forestry is associated with lower deforestation in studies where this is the variable of interest $(-15|24|+1)$, but is associated with higher deforestation in studies where this variable is a control only $(-22|42|+28)$. Timber activity is associated with lower deforestation in economics journals $(-4|6|+0)$ but is associated with higher deforestation in other journals $(-33|14|+40)$. And both timber activity and timber price are associated with lower deforestation in Latin America (timber activity: $-11|6|+7$; timber price: $-27|20|+1$ ) but higher deforestation in Asia (timber activity: $-26|14|+33$; timber price: $-0|12|+18)$.

One particular form of community forestry, the Mexican communal property arrangement known as an ejido, has been particularly well studied (e.g. Deininger and Minten 1999; Ellis 
and Porter-Bolland 2008; Barsimantov and Kendall 2012; Perez-Verdin et al), and here results are mixed as well $(-12|23|+13)$. Some studies have concluded that ejidos reduce deforestation through better forest governance (Barsimantov and Kendall 2012), while other studies suggest that ejidos increase deforestation by encouraging the expansion of development and pasture (Rueda 2010).

Land tenure security shows no consistent association with either higher or lower deforestation $(-24|30|+20)$. On the one hand, insecure property rights can reduce the present value of standing forests and encourage conversion in order to assert the productive use of land and to reduce expropriation risk, as has been found in Brazil (Araujo et al 2009), Haiti (Dolisca 2007), and Malawi (Place and Otsuka 2001). And more secure property rights for Indigenous Peoples has been found to be associated with lower deforestation in Panama (Nelson 2001). On the other hand, more secure land tenure can increase investment. On the whole, more secure tenure is not consistently influential in the deforestation decision relative to other factors (eg Wyman and Stein 2010). The association between tenure security and deforestation is also sensitive to a variety of disaggregations. More secure tenure is consistently associated with lower deforestation in studies where this is the variable of interest $(-4|0|+0)$, but evidence is mixed in studies where this variable is a control only ($20|30|+20$ ). More secure tenure is associated with lower deforestation in economics journals $(-8|3|+2)$ but not in other journals $(-16|27|+18)$.

Protected areas have been well studied $(\mathrm{n}=35 / 117)$, and of the twenty most-studied metavariables protected areas are the one most consistently associated with lower deforestation ($167|104|+29)$. The analytical question has been whether lower deforestation in protected areas is due to their legal status or to their geographical remoteness (e.g. Nelson 2001; Cropper 2001). On average, protected areas inhibit deforestation, as in Brazil (Soares-Filho 2010), though recent studies employing matching methods in Costa Rica (Andam et al 2008; 
Pfaff et al 2009) and Indonesia (Gaveau et al 2012), have shown that this effect is lower than would be suggested by inside-outside comparisons that don't control for land characteristics. Protected areas' effect varies by management type. The apparent greater impacts of multiple-use managed areas than strict areas (Nelson and Chomitz 2012) may be reversed after controlling for the greater risk of these lands in the absence of intervention (Ferraro et al 2013). The associations between protected areas and deforestation were robust across level of analysis, focus of study, discipline of journal, world region, and dependent variable. Further reviews of the effectiveness of protected areas on stopping deforestation are found in Miteva (2012) and Nelson and Chomitz (2012). Indigenous peoples are also consistently associated with lower deforestation $(-16|72|+6)$. The frequency of outputs showing a not significant association with deforestation suggest that the influence of Indigenous peoples may often be to maintain low rates of deforestation in areas with low levels of baseline threat based on geographical characteristics (e.g. Deininger and Minten, 2002), rather than to reduce rates of deforestation in areas with high levels of baseline threat (e.g. Muller et al 2012). Law enforcement outside of protected areas is also consistently associated with lower deforestation $(-38|9|+4)$.

Variables related to rural income (e.g. poverty; rural income support; off-farm employment; payments for ecosystem services) were studied in $42 / 117$ studies. Greater poverty was consistently associated with lower rates of deforestation $(-105|161|+57)$. Exploration of changes in rural income over time presented a mixed picture. Some studies have found evidence that rising incomes slowed and reversed the loss of forest cover, as in Vietnam (Muller and Zeller 2003) and China (Gong 2013), but other studies have found that greater income led to greater deforestation in China (Li 2013) or had no effects on trends in forest cover in Brazil (Baptista and Rudel 2006), Panama (Sloan 2008), China (Zhao et al 2011), and Mexico (Vaca 2012). A broader meta-analysis and synthesis of studies of the so-called "Environmental Kuznets Curve for deforestation" found the evidence supporting the theory 
to be mixed and diminishing over time (Choumert et al 2013). Though the consistent association between poverty and lower deforestation was robust across level of analysis, discipline of journal, world region, and dependent variable, it is nonetheless worth noting that findings diverged based on whether or not poverty was the focus of the study. In studies where poverty was the variable of interest, poverty was consistently associated with higher deforestation $(-15|50|+32)$, while in studies where poverty was a control only, poverty was consistently associated with lower deforestation $(-90|111|+25)$.

Of course, absent careful study design, the changes in deforestation that can be directly attributed to poverty or to changes in income or wealth are difficult to separate from concurrent geographical or temporal trends that also affect deforestation. Clearer evidence is provided where incomes are changed directly by rural income support programs in the form of public loans, subsidies or payments. Here a more consistent pattern emerges: increased income from rural support programs is consistently associated with increased rates of deforestation (-11|59|+34), as in Mexico (Klepeis and Vance 2003). A quasiexperimental study by Alix-Garcia et al (2013) found that increased income from a rural support program in Mexico raised the consumption of land-intensive goods and increased deforestation, especially in more remote communities. The association between rural income support and deforestation is sensitive to a variety of disaggregations. Rural income support is associated with lower deforestation in studies where this is the variable of interest $(-4|0|+0)$, but associated with higher deforestation in studies where this variable is a control only $(-7|53|+34)$. Rural income support is associated with higher deforestation in economics journals $(-2|40|+27)$ but is associated with lower deforestation in other journals $(-9|19|+7)$. And rural income support is associated with lower levels of forest cover ($2|40|+27)$ but lower rates of deforestation $(-9|19|+7)$. 
A different picture emerges when increases in income are tied directly to the maintenance of forest cover through payments for ecosystem services (PES) $(-21|17|+6)$. While early research found little effect of PES on deforestation rates in Costa Rica (e.g. SanchezAzofeifa 2007), subsequent studies found PES in Costa Rica to have had a positive effect on total forest cover, which includes forest regrowth in addition to deforestation (Alix-Garcia et al 2012; Arriagada 2012). This finding is consistent with the fact that Costa Rica was experiencing forest regrowth rather than deforestation during the period studied. HoneyRoses (2011) found that PES combined with protected areas slowed deforestation in Mexico. On the whole the evidence base on PES is still limited (4/117), and the entire evidence base comes from studies where PES was the focus of study. Further reviews of the effectiveness of PES on stopping deforestation are found in Pattanayak et al (2010) and Miteva (2012).

Variables related to community demographics such as age $(-8|33|+3)$, education ($14|19|+14$ ), gender (more females: $-3|19|+7)$, or property size $(-15|32|+7)$ had no consistent association with either higher or lower deforestation, as in Brazil (Van Wey 2007) and Mexico (Perez-Verdin 2009).

Population was included as a meta-variable in 50/117 studies. While there is a strong association between greater population and greater deforestation $(-41|178|+136)$ that is robust across level of analysis, focus of study, discipline of journal, world region, and dependent variable, this relationship is difficult to interpret (Rosero-Bixby 1998). On one hand, population can increase deforestation by increasing the supply of labor and the local demand for agricultural products. On the other hand, population growth occurs simultaneously with other rural economic expansion that increases deforestation pressure, and an increase in cleared land can support a greater population. We did not find any study that attempted to disentangle the endogeneity between population growth and deforestation. 
Furthermore, the relationship between population growth and deforestation may not be straightforward. Pfaff (1999) found that the first migrants to a county had greater impact on deforestation than later immigrants in Brazil. Defries et al (2010) found that forest loss across forty-one countries was positively correlated with urban population growth and exports of agricultural products, rather than with rural population growth, suggesting the importance of urban-based and international demands for agricultural products as drivers of deforestation.

Finally, proximity to cleared land is consistently associated with greater deforestation ($62|60|+111)$. This result is robust across level of analysis, focus of study, discipline of journal, world region, and dependent variable. It is unclear the extent to which this result is a consequence of increased access and reduced clearing costs rather than omitted variables that are correlated with greater likelihood of deforestation.

Encouragingly, we did not find evidence that the studies in our database were persistently biased toward the publication of "more significant" results. In fact polarized variables that were the focus of a study were significant slightly less often $(401 / 729 ; 55 \%)$ than polarized variables that were not the focus of a study $(2477 / 4069 ; 61 \%)$. Furthermore the sign was the same between the two types for all but four of the meta-variables studied (Figure 4).

However, it is worth noting that all four of the meta-variables for which the sign diverged based on whether or not the variable was the focus of the study were related to somewhat controversial or ideologically charged topics for which publication bias might be more suspected: community forestry, land tenure security, poverty, and rural income support. Except where specifically described in the text above, associations between meta-variables and deforestation were in agreement across levels, across journal disciplines, across world regions, and across focus of study. 


\section{Discussion}

\section{What drives deforestation?}

Competition for the use of land between forests and agriculture would have come as no surprise to Johann Heinrich von Thunen. Von Thunen devised the first quantitative spatial model of land use, in which land is allocated to the use that provides people with the highest economic return (von Thunen, 1826). This return is diminished as transportation costs increase, such that economic activities with relatively high transportation costs (e.g. dairy in von Thunen's original model) would locate near cities while activities with lower costs (e.g. livestock grazing) would occur farther away.

Von Thunen's two-centuries-old theory that the spatial allocation of land use will be determined by economic returns remains strong today as an explanation for present-day patterns of deforestation. In particular, forests are more likely to be cleared where the economic returns to agriculture and pasture are higher, either due to more favorable climatological and topographic conditions, or due to lower costs of clearing forest and transporting products to market. Where forests can produce economic returns through products, services, or amenities, economic exploitation of forests may forestall more rapid conversion to agricultural use, even while potentially degrading the forest and opening up greater access for clearing later. Rival explanatory theories of the pattern of deforestation based on land tenure security and community demographics are not as consistently supported by econometric results. Furthermore, it is frequently difficult to disentangle the effect of some variables such as population or poverty on deforestation from the effects of concurrent geographical or temporal trends.

\section{What stops deforestation?}

For decision makers seeking to curtail deforestation, this meta-analysis suggests a number of promising approaches. Road networks can be planned to minimize their intrusion into 
remote forest areas. Protected areas can be targeted to highly threatened areas. While rural income support generally increases deforestation, with some sensitivity to disaggregation, income support that is tied to the maintenance of the forest resource (e.g. PES) appears promising from limited published research to date. Policies that insulate the forest frontier from the price effects of demand for agricultural commodities have potential for success, though it is beyond the scope of this paper to assess which policies are able to do so effectively. As an overarching policy, international payments for reducing emissions from deforestation and forest degradation (REDD+) would increase the rewards for successfully undertaking any of the above interventions.

Some commonly suggested "win-win" approaches for stopping deforestation are not borne out by the econometric results of our meta-analysis. Securing land tenure, while potentially good for development outcomes, does not show a consistent relationship with lower deforestation outside of Indigenous territories. There is also not consistent evidence that higher income is sufficient on its own to slow and reverse deforestation without additional deliberate policy interventions.

Policies to support "working forests" (e.g. logging concessions; timber plantations; shadegrown coffee; agroforestry; community forestry) appear to have a mixed effect on forest cover. On the one hand, the economic returns that such activities provide may forestall more rapid conversion to agricultural land use. On the other hand, these activities can degrade forests and provide greater access for subsequent conversion. Thus policies to support working forests may be better suited to restoration of secondary forest cover rather than maintenance of more biodiverse primary forest.

Our findings are broadly in accord with those of previous reviews of drivers of deforestation (Angelsen and Kaimowitz 1999, Geist and Lambin 2002, Rudel 2009, Angelsen and Rudel 2013, Pfaff et al 2013); see Table 4 for a comparison of how our findings for the twenty 
most commonly studied meta-variables compare to those of previous studies. Our paper differs from previous reviews in that it restricts the scope of evidence to spatially explicit econometric studies of deforestation, is comprehensive within this scope, and is current. Most importantly, our meta-analysis is quantitative where previous reviews have been qualitative. This quantitative analysis allows us to compare the relative influence of driver variables on deforestation and to assess the relative size of the evidence base for each driver.

\section{Directions for future research}

This meta-analysis suggests a number of gaps that could be usefully addressed through further research. The geographical evidence base on which our collective econometric understanding of deforestation rests is weighted heavily toward a few well studied countries. More than half of the 117 studies were from just six countries: Mexico ( $\mathrm{n}=22)$; Brazil $(\mathrm{n}=15)$; Costa Rica $(\mathrm{n}=8)$; China $(\mathrm{n}=5)$; Indonesia $(\mathrm{n}=5)$; and Thailand $(\mathrm{n}=5)$. This geographical emphasis has likely been due to the availability of data in many of these countries in addition to policy interest. Regions where spatially explicit econometric study of land-use change lags behind these regions' share of forest cover and deforestation include North America, Eastern and Northern Europe, West and Central Africa, and Australia and

New Zealand (Table 5). With the public release of annual globally consistent 30-m resolution data on forest cover change (Hansen 2013), data availability gaps for other regions are closing. The gap in spatially explicit econometric analysis should close in these understudied regions as well. These new globally consistent data will also allow more multi-national analyses, which have been limited to four studies to date.

Nearly all studies to date have relied upon forest cover change data with time increments of five to ten years (mean increment $=7.7$ years; Table 1 ). The public availability of forest loss data at sub-monthly time intervals will allow the use of more sophisticated panel econometric techniques than can be applied to cross-sectional data (e.g. Wheeler et al 2012). 
This newly available data can be used to testing more granular analysis of when deforestation happens in addition to where deforestation happens, and to more closely analyze the trajectory of deforestation through time in response to drivers such as roads or land management designations.

Rigorous impact evaluations currently comprise only a small minority of spatially explicit econometric studies of deforestation. Quasi-experimental methods are especially important and lacking for determining the effect of variables that are endogenous with deforestation such as poverty and population.

Almost all studies to date have explored drivers of deforestation rather than forest degradation. Improvements in remote sensing soon can be expected to enable exploration of forest degradation and its drivers as well.

For a number of topics, limited econometric evidence lags growing policy interest. Topics for which the evidence base would be usefully strengthened with further study include payments for environmental services, law enforcement, forest and commodity certification, mining, and gender. 


\section{Concluding thoughts}

Spatially explicit econometric studies of deforestation have proliferated rapidly since their introduction two decades ago. Until now a fragmented literature has impeded the development of well-grounded conclusions regarding the relative influence of alternative driver variables on deforestation. By examining more than one hundred studies collectively, our meta-analysis shows the level of agreement across studies on the relationship of driver variables with deforestation, as well as the size of the evidence base. We have also identified drivers where findings diverge based on whether or not that driver was the focus of study. We have solidified theory of what drives deforestation and have suggested promising strategies for stopping it. This knowledge can be put to use by public agencies seeking to conserve forests for their many public and private values. 


\section{References}

Alix Garcia, J., et al. (2013). The Ecological Footprint of Poverty Alleviation: Evidence from Mexico's Oportunidades Program. The Revew of Economics and Statistics, 95(2):417.

Andam, K.S., et al. (2008). Measuring the Effectivness of Proteced Area Networks in Reducing Deforestation. PNAS, vol. 105 no. 42 16089-16094

Angelsen, A. and Kaimowitz, D.(1999). Rethinking the causes of deforestation: Lessons from economic models. The World Bank Research Observer, 14:73-98.

Angelsen, A. and Rudel, T.K. (2013). Designing and Implementing Effective REDD + Policies: A Forest Transition Approach. Review of Environmental Economics and Policy, 7(1):91-113.

Arima, E.Y. et al. (2011). Statistical Confirmation of Indirect Land Use Change in the Brazilian Amazon. Environmental Research Letters, 6(2):024010.

Araujo, C. et al. (2009). Property Rights and Deforestation in the Brazilian Amazon. Ecological Economics, 68(8-9): 2461-2468.

Banfai, D. S. and Bowman, M. J. S. (2007). Drivers of Rain-Forest Boundary Dynamics in Kakadu National Park, Northern Australia: A Field Assessment. Journal of Tropical Ecology, 23(1): 73 - 86.

Baptista, S.R. and Rudel, T.K. (2006). A Re-Emerging Atlantic Forest? Urbanization, Industrialization and the Forest Transition in Santa Catarina, Southern Brazil.

Barsimantov, J. and Kendall, J. (2012). Community Forestry, Common Property, and Deforestation in Eight Mexican states. The Journal of Environment Development, 21(4): 414-437.

Blackman, A. et al. (2008). Land Cover in a Managed Forest Ecosystem: Mexican Shade Coffee. American Journal of Agricultural Economics, 90(1): 216-231.

Blackman, A., et al. (2012). Land Cover Change in Agroforestry: Shade Coffee in El Salvador. Land Economics, 88(1): 75-101.

Brown, S., Iverson, L.R. and Lugo, A. 1993 Land use and biomass changes in Peninsular Malaysia during 1972-1982: use of GIS analysis. In: Dale, V.H. (ed.) Effects of land-use change on atmospheric CO2 concentrations: Southeast Asia as a case study. Springer Verlag, New York.

Burgess, R., et al. (2012). The Political Economy of Deforestation in the Tropics. Quarterly Journal of Economics, 127(4): 1707-1754.

Busch, J. et al. (2011). Structuring Economic Incentives to Reduce Emissions from Deforestation within Indonesia. Proceedings of the National Academy of Sciences of the United States of America, 109(4):1062-1067.

Chomitz, K., Gray, D. (1996) Roads, Land Use, and Deforestation: A Spatial Model Applied to Belize. World Bank Economic Review, 10(3): 487-512

Chomitz, K. and Thomas, T. (2003) Determinants of Land Use in Amazonia: A Fine-Scale Analysis. American Journal of Agricultural Economics, 85(4): 1016-1028.

Chowdhury, R.R. (2006). Driving forces of tropical deforestation: The role of remote sensing and spatial models. Singapore Journal of Tropical Geogrpahy, 27(1): 82-101.

Cropper, M. et al. (2001). Predicting the Location of Deforestation: The Role of Roads and Protected Areas in North Thailand. Land Economics, 77(2) 172-186. 
Choumert, J., Combes-Motel, P., Dakpo, H.K. (2013). Is the Environmental Kuznets Curve for deforestation a threatened theory? A meta-analysis of the literature. Ecological Economics 90:19-28.

Deininger, K. W. and Minten, B. (1999). Poverty, Policies, and Deforestation: The Case of Mexico. Economic Development and Cultural Change, 47(2): 313-344.

Deng, X., et al. (2011). Pressure Cookers or Pressure Valves: Do Roads Lead to Deforestation in China? Journal of Environmental Economics and Management, 61(1): 79.

Defries, R.S., et al. (2010). Deforestation Driven By Urban Population Growth and Agricultural Trade in the Twenty-First Century. Nature Geoscience, 3(3), 178-181.

Dolisca, F., et al. (2007). Land Tenure, Population Pressure, and Deforestation in Haiti: The Case of Forêt des Pins Reserve. Journal of Forest Economics, 13(4): 277.

Ehrhardt-Martinez, K. (1998) Social Determinants of Deforestation in Developing Countries: A Cross-National Study. Social Forces, 77(2):567-586.

Ellis, E. A. and Porter-Bolland, L. (2008). Is Community-Based Forest Management More Effective Than Protected Areas? A Comparison of Land Use/Land Cover Change in Two Neighboring Study Areas of the Central Yucatan Peninsula, Mexico. Forest Ecology and Management, 256(11): 1971-1983.

Ellis, E. A., et al. (2010). Land Use/Land Cover Change Dynamics and Drivers in a allowGrade Marginal Coffee Growing Region of Veracruz, Mexico. Agroforestry Systems, 80(1): 61-84.

Ferraro, P.J., et al. (2013). More Strictly Protectetd Areas Are Not Necessarily More Protective: Evidence from Bolivia, Costa Rica, Indonesia, and Thailand. Env Res Let, 8, 025011.

Food and Agricultural Organization of the United Nations (2010) Global Forest Resources Assessment 2010 (Food and Agricultural Organization of the United Nations, Rome).

Gaveau, D.L.A. et al. (2009). Three Decades of Deforestation in Southwest Sumatra: Effects of Coffee Prices, Law Enforcement and Rural Poverty. Biological Conservation, 142(3): 597-605.

Gaveau, D.L.A., et al. (2012). Examining Protected Area Effectiveness in Sumatra: Importance of Regulations Governing Unprotected Lands. Conservation Letters, 5(2): 142-148.

Gaveau, DLA, et al. (2013). Reconciling Forest Conservation and Logging in Indonesian Borneo. PLoS ONE 8(8): e69887.

Geist, H.J., and Lambin, E.F. (2002). Proximate causes and underlying driving forces of tropical deforestation. BioScience 52:143-150.

Getahun, K. et al. (2013). Factors Controlling Patterns of Deforestation in Moist Evergreen Afromontane Forests of Southwest Ethiopia, 304: 171-181.

Gibbs, H.K., Ruesch, A.S., Achard, F., Clayton, M.K., Holmgren, P., Ramankutty, N., Foley, J.A (2010). Tropical forests were the primary sources of new agricultural land in the 1980s and 1990s. Proceedings of the National Academy of Sciences, 107:16732-16737.

Godoy, R. et al. (1998). The Role of Education in Neotropical Deforestation: Household Evidence from Amerindians in Honduras. Human Ecology, 26(4): 649-675.

Gong, Chongfeng. 2013. Determining socioeconomic drivers of urban forest fragmentation with historical remote sensing images, Landscape and urban planning, 117, 57 - 65-65. 
Hansen, M.C., et al. (2013) High-Resolution Global Maps of 21st-Century Forest Cover Change. Science 342-850-853.

Hargrave, J., and Kis-Katos, K. (2012). Economic Causes of Deforestation in the Brazilian Amazon: A Panel Data Analysis for the 2000s. Environmental and Resource Economics, 54: 471-494.

Higgins, J.P.T., Green, S. (2011). Cochrane Handbook for Systematic Reviews of Interventions Version 5.1.0. The Cochrane Collaboration. Johns Hopkins School of Public Health, Baltimore, MD.

Hosonuma, N., Herold, M., De Sy, V., De Fries, R.S., Brockhaus, M., Verchot, L., Angelsen, A., Romijn, E. (2012). An assessment of deforestation and forest degradation drivers in developing countries. Environmental Research Letters 7:044009.

Kerr, S., et al. (2002). The Dynamics of Deforestation: evidence from Costa Rica. Working paper, 69(1): 25-37.

Klepeis, P. and Vance, C. (2003). Neoliberal Policy and Deforestation in Southeastern Mexico: An Assessment of the PROCAMPO Program. Economic Geography, 79(3): 221-221.

Li, Y., et al. (2013). Effects of conservation policies on forest cover change in giant panda habitat regions, China. Land Use Policy, 33: 42-53.

Lambin, E.F. (1994). Modelling deforestation processes: a review. Official Publications of the European Community, 16744 EN.

Lopez, S et al. (2010). Tropical Deforestation in Ecuadorian Chocó: Logging Practices and Socio-Spatial Relationship. The Geographical Bulletin, 51(1): 3-22.

Mertens, B. and Lambin, E. F. (2000). Land-Cover-Change Trajectories in Southern Cameroon. Annals of the Association of American Geographers, 90(3):467-494.

Miteva, D.A., Pattanayak, S.K., Ferraro, P.J. (2012). Evaluation of biodiversity policy instruments: what works and what doesn't? Oxford Review of Economic Policy, 28:69-92.

Muller, R. et al. (2012). Proximate causes of deforestation in the Bolivian lowlands: an analysis of spatial dynamics. Regional Environmental Change, 12: 445-459.

Muller, D. and Zeller, M. (2002) Land use dynamics in the central highlands of Vietnam: a spatial model combining village survey data with satellite imagery interpretation.

Agricultural Economics, 27(3): 333-354.

Myers, S.S., Gaffikin, L., Golden, C.D., Ostfeld, R.S., Redford, K.H. Ricketts, T.H., Turner, W.R., Osofsky, S.A. (2013). Human health impacts of ecosystem alteration. Proceedings of the National Academy of Sciences www.pnas.org/cgi/doi/10.1073/pnas.1218656110.

Nelson, G. C. and Hellerstein, D. (1997). Do Roads Cause Deforestation? Using Satellite Images in Econometric Analyses of Land Use. American Journal of Agricultural Economics, 79(1): 80-88.

Nelson, G.C., et al. (2001). Deforestation, Land Use, and Property Rights: Empirical Evidence from Darien, Panama. Land Economics, 77(2): 187-205.

Nelson, A. and Chomitz, K.M. (2011). Effectiveness of Strict vs. Multiple Use Protected Areas in Reducing Tropical Forest Fires: A Global Analysis Using Matching Methods. PLoS One, 6(8): e22722.

Pattanayak, S.K., Wunder, S., and Ferraro, P.J. (2010). Show me the money: Do payments supply environmental services in developing countries? Review of Environmental Economics and Policy, 4(2):254-274. 
Perez-Verdin, G. et al. (2009). Factors Driving Deforestation in Common-Pool Resources in Northern Mexico. Journal of Environmental Management, 90(1): 331-340.

Pfaff, A. S. P. (1999). What drives Deforestation in the Brazilian Amazon? Evidence from Satellite and Socioeconomic Data. Journal of Environmental Economics and Management. 37(1): 26-43

Pfaff, A. et al. (2007a). Road Investments, Spatial Spillovers, and Deforestation in the Brazilian Amazon. Journal of Regional Science, 47(1): 109-123.

Pfaff, A.S.P., et al. (2007b). Will Buying Tropical Forest Carbon Benefit the Poor? Evidence From Costa Rica. Land Use Policy, 24: 600-610.

Pfaff, A. et al. (2009). Park Location Affects Forest Protection: Land Characteristics Cause Differences in Park Impacts Across Costa Rica. B.E. Journal of Economic Analysis \& Policy, 9(2): 1-24.

Pfaff, A., Amacher, G.S., and Sills, E.O. (2013). Realistic REDD: Improving the Forest Impacts of Domestic Policies in Different Settings. Review of Environmental Economics and Policy, 7:114-135.

Place, F. and Otsuka, K. (2001). Population, Tenure, and Natural Resource Management: The Case of Customary Land Area in Malawi. Journal of Environmental Economics and Management, 41: 13-32.

Raven, P.H. (1988). Our diminishing tropical forests. In: E.O. Wilson (ed.) Biodiversity. National Academy Press, Washington, DC, USA.

Rosero-Bixby, L., and Palloni, A. (1998). Population and Deforestation in Costa Rica. Population and Environment, 20(2): 149.

Rueda, X. (2010). Understanding Deforestation in the Southern Yucatan: Insights from a Sub-Regional, Multi Temporal Analysis. Regional Environmental Change, 10(3): 175189.

Rudel, T.K., et al. (2009). Changing Drivers of Deforestation and New Opportunities for Conservation. Conservation Biology, 23(6): 1396-1405.

Sanchez-Azofeifa, G.A., et al. (2007). Costa Rica's payment for environmental services program: Intention, implementation and impact. Conservation Biology 21(5):1165-1173.

Sangermano, F., et al. (2012). Land Cover Change in the Bolivian Amazon and its Implications for REDD+ and Endemic Biodiversity. Landscape Ecology, 27(4): 571584.

Sloan, S. (2008). Reforestation Amist Deforestation: Simultaneity and Succession. Global Environmental Change, 18(3): 425-441.

Soares-Filho, et al. (2010). Role of Brazilian Amazon Protected Areas in Climate Change Mitigation. Proceedings of the National Academy of Sciences, 107(24): 10821-10826.

Takahashi, R., and Todo, Y. (2012). Impact of Community-Based Forest Management on Forest Protection: Evidence from an Aid-Funded Project in Ethiopia. Environmental Management, 50: 396-404.

Turner, M.G., et al. (1996). Land Ownership and Land-Cover Change in the Southern Appalachian Highlands and the Olympic Peninsula. Ecological Applications, 6(4): 11501172.

UNFCCC (2013). Decision -/CP.19. Addressing the drivers of deforestation and forest degradation. United Nations Framework Convention on Climate Change. Bonn, Germany. 
Vaca, R.A., et al. (2012). Evidence of Incipient Forest Transition in Southern Mexico. PLoS One 7(*): e42309. doi:10.1371/journal.pone.0042309.

van der Werf, G.R. et al. (2009). CO2 emissions from forest loss. Nature Geoscience, 2:737738

VanWey, L. K., et al. (2007). Household Demographic Change and Land Use/Land Cover Change in the Brazilian Amazon. Population Environment, 28(3): 163-185.

von Thünen, J. H. (1826). Der isolierte Staat in Beziehung auf Landwirtschaft und Nationaloekonomie Jena.

Weinhold, D. and Reis, E. (2008). Transportation Costs and the Spatial Distribution of Land Use in the Brazilian Amazon. Global Environmental Change, 18: 54-68.

Wheeler, D. et al. (2013). Economic Dynamics and Forest Clearing: A Spatial Econometric Analysis for Indonesia. Ecological Economics, 85: 85-96

Wyman, M. S., and Stein, T. V. (2010). Modeling Social and Land-Use/Land-Cover Change Data to Assess Drivers of Smallholder Deforestation in Belize. Applied Geography, 30 (3) 329-342.

Zhao, H. et al. (2011). Do Trees Grow with the Economy? A Spatial Analysis of the Determinants of Forest Cover Change in Sichuan, China. Environmental and Resource Economics, 50: 61-82. 
10

6

4

2

0

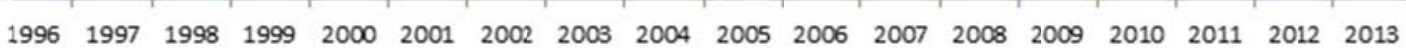

Figure 1. Growth over time in spatially explicit econometric studies of deforestation, by region. 


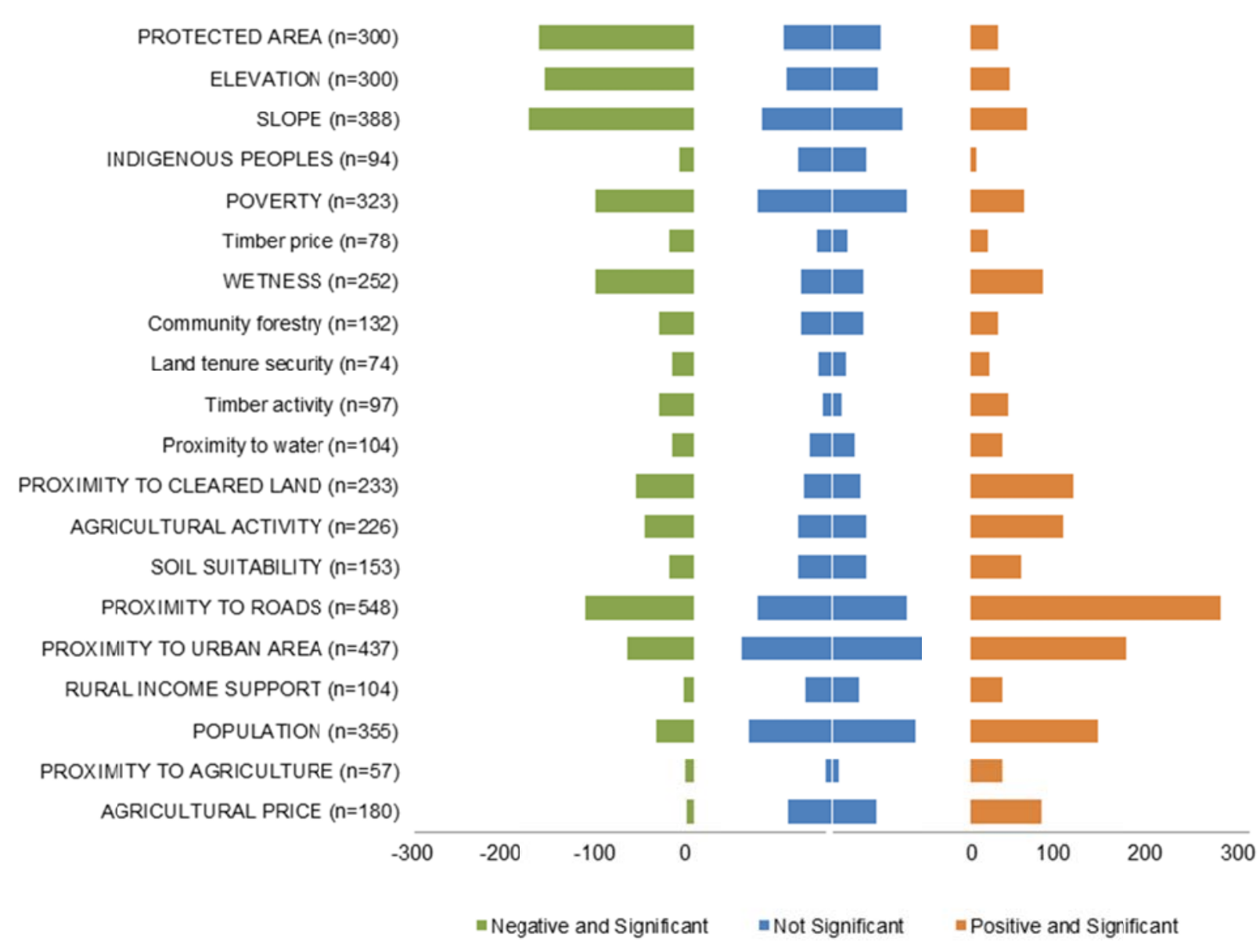

Figure 2. Twenty most commonly studied metavariables' association with deforestation, organized by sign and significance of coefficients related to that meta-variable. Meta-variables ordered by ratio of negative to positive association with deforestation. Metavariables with fewer than 55 coefficients not displayed. For meta-variables in upper case, the ratio of negative to positive observations is statistically significantly different from 1:1 in a two-tailed t-test at the $95 \%$ confidence level. 


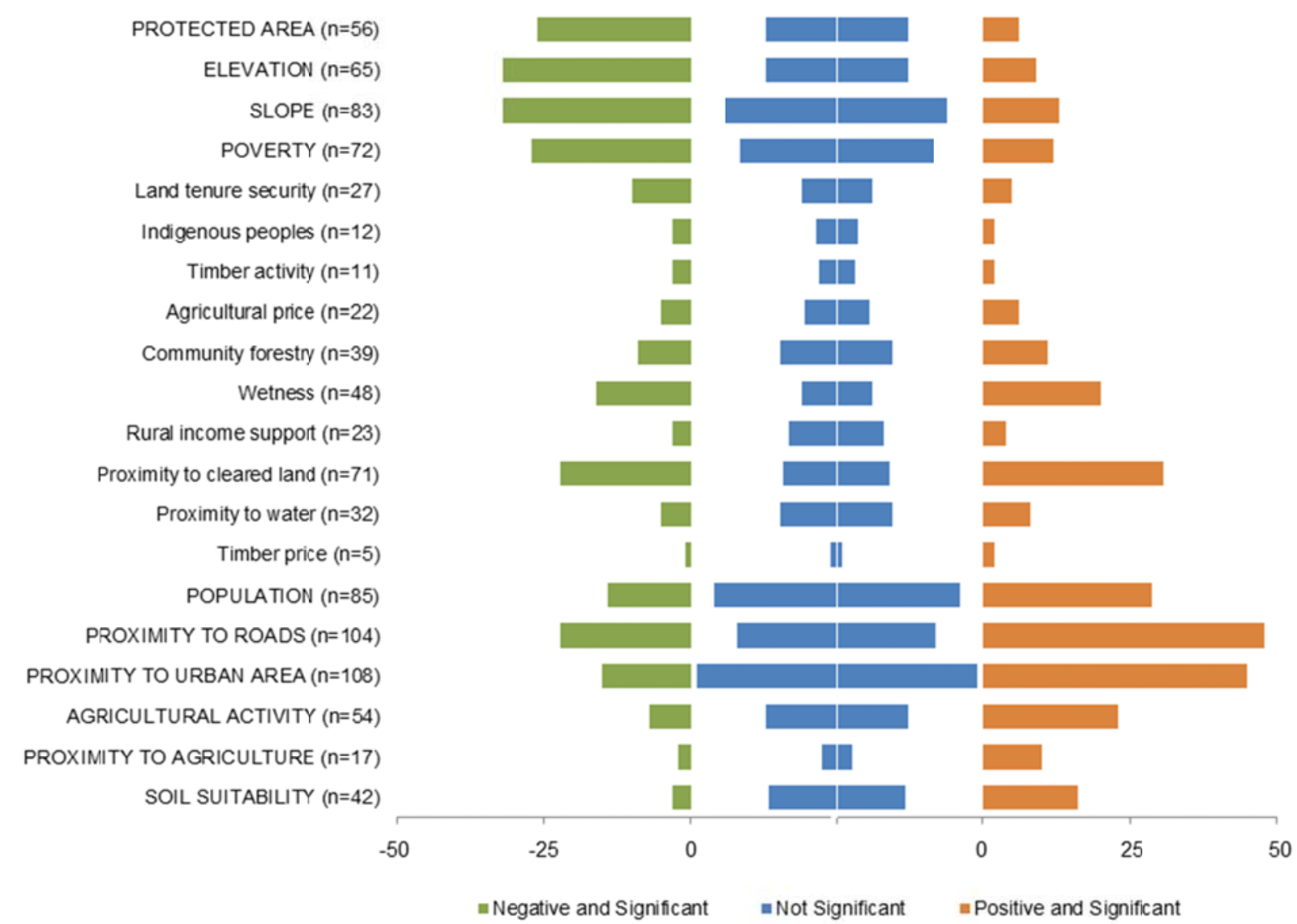

Figure 3. Twenty most commonly studied metavariables' association with deforestation, organized by sign and significance of studylevel plurality of coefficients related to that meta-variable. Meta-variables ordered by ratio of negative to positive association with deforestation. Meta-variables with fewer than 55 coefficients not displayed. For meta-variables in upper case, the ratio of negative to positive observations is statistically significantly different from 1:1 in a two-tailed t-test at the $95 \%$ confidence level. 
Regression Level Outcomes, (Non-Focus, Focus)

(ordered by ratio of negative to positive association with deforestation)

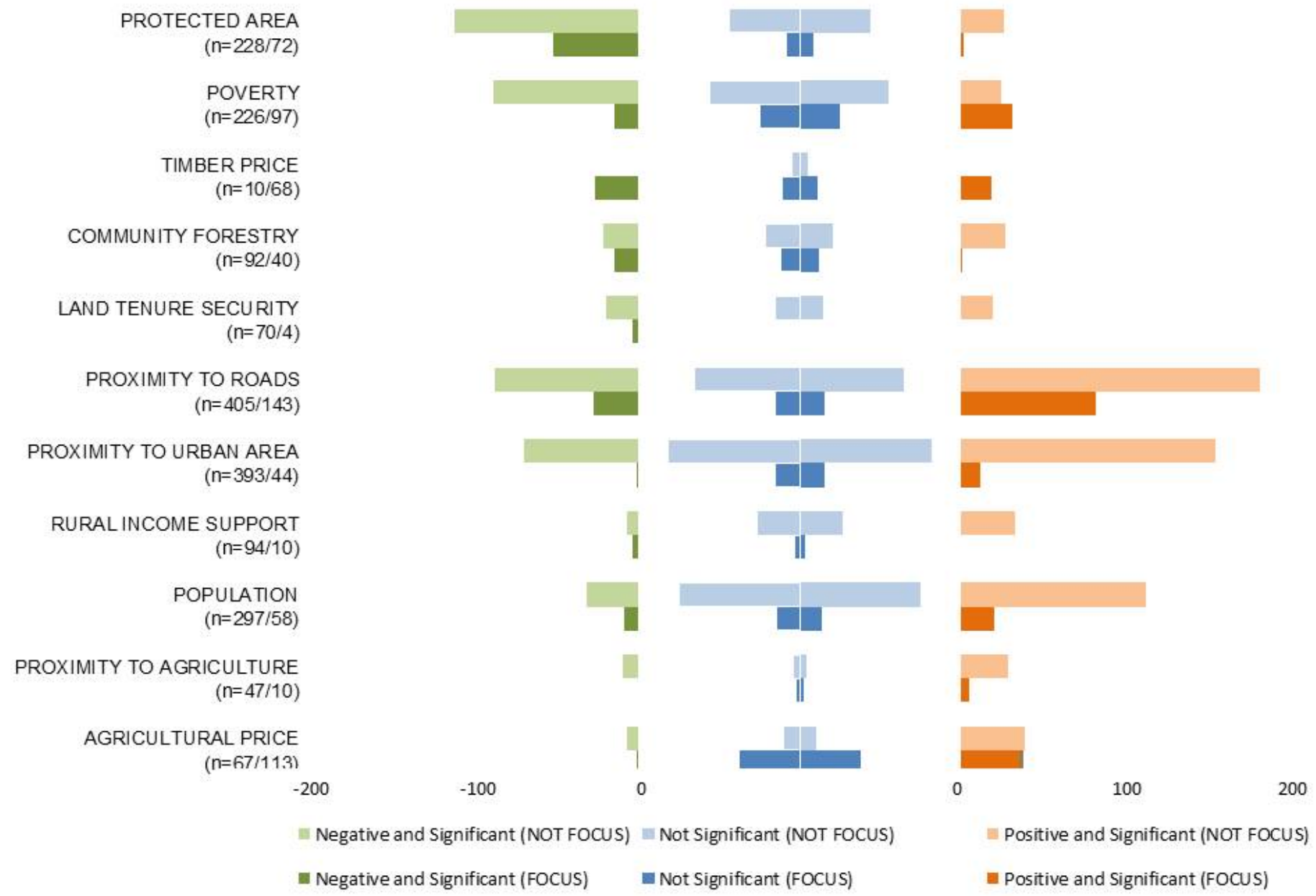

Figure 4. Twenty most commonly studied metavariables' association with deforestation, organized by sign and significance of coefficients related to that meta-variable, disaggregated by focus of study (variable of interest vs. control variable). Meta-variables ordered by ratio of negative to positive association. Meta-variables with fewer than 55 regression results not displayed. Meta-variables that were never the focus of study not displayed. 


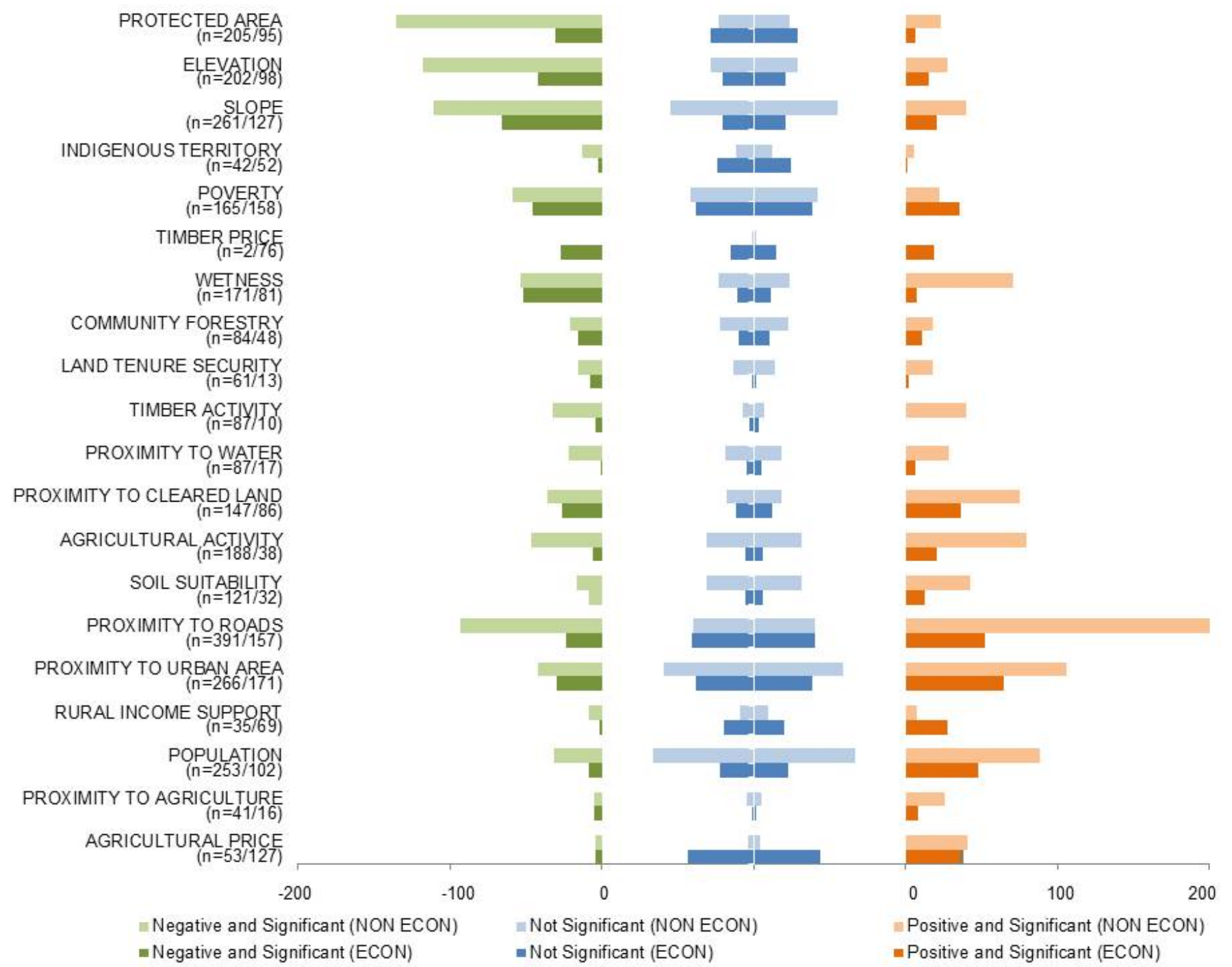

Figure 5. Twenty most commonly studied metavariables' association with deforestation, organized by sign and significance of coefficients, disaggregated by discipline of journal (economics vs. non-economics). Meta-variables ordered by ratio of negative to positive association. Meta-variables with fewer than 55 regression results not displayed. 


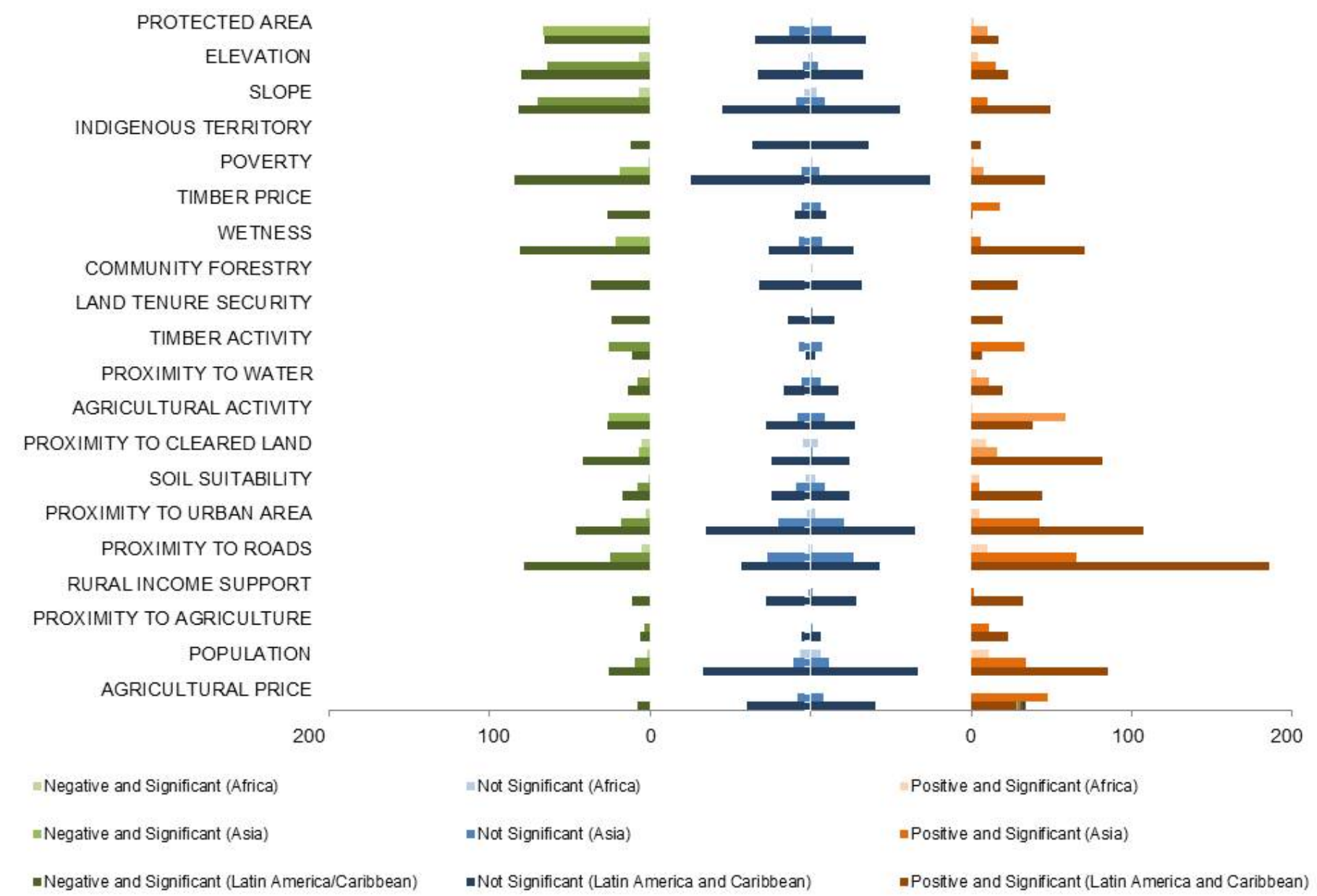

Figure 6. Twenty most commonly studied metavariables' association with deforestation, organized by sign and significance of coefficients related to that meta-variable, disaggregated by world region (Africa, Asia, or Latin America/Caribbean). Meta-variables ordered by ratio of negative to positive association. Meta-variables with fewer than 55 regression results not displayed. 


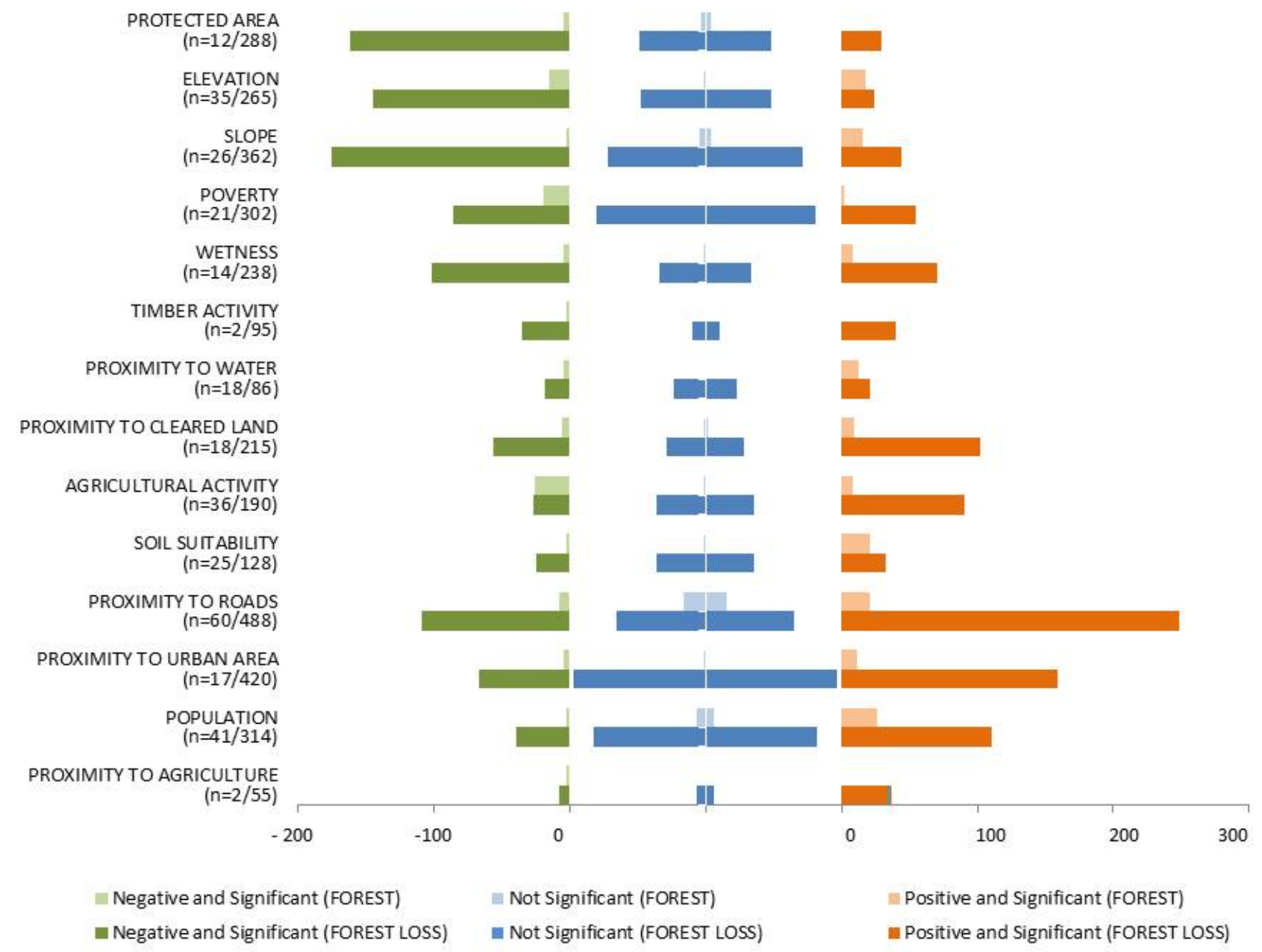

Figure 7. Twenty most commonly studied metavariables' association with deforestation, organized by sign and significance of coefficients related to that meta-variable, disaggregated by character of dependent variable (forest cover (sign inverted) or forest loss), ordered by ratio of negative to positive association. Meta-variables with fewer than 55 regression results not displayed. Meta-variables for which all dependent variables were related to forest loss rather than forest cover not displayed. 
Table 1. Keywords searched.

\begin{tabular}{|l|l|}
\hline Subject & Method \\
Afforest* & Binomial \\
Defor* & Econometric* \\
Land Cover & Logi* \\
Land Use & Matching \\
LUC & Multinomial \\
REDD* & Multivariate \\
Concept & Neural Net* \\
Caus* & OLS \\
Determ* & Ordinary Least Square* \\
Driv* & Poisson \\
Model & Probit \\
Spatial* & Regress* \\
\hline
\end{tabular}


Table 2. Studies included $(n=117)$.

\begin{tabular}{|c|c|c|}
\hline Turner et al, Ecol Applic, 1996 & Baptista and Rudel, Env Cons, 2006 & Lin et al, Int J Geog Info Sci, 2011 \\
\hline Nelson and Hellerstein, Am J Agric Econ, 1997 & Pfaff et al, J Reg Sci, 2007 & Nakakaawa et al, Mitig Adapt Strat Glob Change, 2011 \\
\hline Wear and Bolstad, Ecosyst, 1998 & Sanchez-Azofeifa et al, Cons Biol, 2007 & Busch et al, Proc Nat Acad Sci, 2011 \\
\hline Rosero-Bixby and Palloni, Pop Env, 1998 & VanWey et al, Pop Env, 2007 & Nelson and Chomitz, PLoS ONE, 2011 \\
\hline de Koning et al, Agric, Ecosyst Env, 1998 & Dolisca et al, J Forest Econ, 2007 & Van Dessel et al, Int J Geog Info Sci, 2011 \\
\hline Pfaff, J Env Econ Manag, 1999 & Pfaff et al, Land Use Policy, 2007 & Wendland et al, Glob Env Change, 2011 \\
\hline Deininger and Minten, Econ Dev Cult Change, 1999 & Alix-Garcia, J Env Econ Mgmt, 2007 & Zhao et al, Env Res Econ, 2011 \\
\hline Cropper, Land Econ, 1999 & Sloan, Glob Env Change, 2008 & Honey-Roses et al, Cons Biol, 2011 \\
\hline Mertens et al, World Dev, 2000 & Ellis and Porter-Bolland, Forest Ecol Manag, 2008 & Deng et al, J Env Econ Manag, 2011 \\
\hline Helmer, Ecosyst, 2000 & Alix-Garcia et al, Env Dev Econ, 2008 & Areki, Afr J Agric Res, 2012 \\
\hline Cropper et al, Land Econ, 2001 & Bray, Ecol Soc, 2008 & Muller et al, Reg Env Change, 2012 \\
\hline Nelson et al, Land Econ, 2001 & Blackman et al, Am J Agric Econ, 2008 & Barsimantov and Kendall, J Env Dev, 2012 \\
\hline Soares-Filho et al, Bioscience, 2001 & Weinhold and Reis, Glob Env Change, 2008 & Vuohelainen et al, Env Manag, 2012 \\
\hline Walsh et al, Agric, Ecosyst Env, 2001 & Caldas et al, Annals Assoc Am Geog, 2008 & Olaniyi et al, Ocean Coast Manag, 2012 \\
\hline Geoghegan et al, Agric, Ecosyst Env, 2001 & Andam et al, Proc Nat Acad Sci, 2008 & van Asselen and Verburg, Glob Change Biol, 2012 \\
\hline Place and Otsuka, J Env Econ Manag, 2001 & Perez-Verdin et al, J Env Manag, 2009 & Lopez-Carr et al, Ecol Model, 2012 \\
\hline Deininger and Minten, Am J Agric Econ, 2002 & Agarwal, Ecol Econ, 2009 & Takahashi and Todo, Env Manag, 2012 \\
\hline Muller and Zeller, Agric Econ, 2002 & Bhattarai et al, J Env Manag, 2009 & Monzon-Alvarado et al, Appl Geog, 2012 \\
\hline Munroe et al, Agric Econ, 2002 & Pfaff et al, B.E. J Econ An Policy, 2009 & de Espindola et al, Appl Geog, 2012 \\
\hline Vance and Geoghegan, Agric Econ, 2002 & Gaveau and Linkie, Biol Cons, 2009 & Vaca et al, PLoS ONE, 2012 \\
\hline Verburg et al, Env Manag, 2002 & De Pinto and Nelson, Env Res Econ, 2009 & Blackman et al, Land Econ, 2012 \\
\hline Tole, GeoJ, 2002 & Gaveau et al, Env Res Lett, 2009 & Alix-Garcia et al, Land Econ, 2012 \\
\hline Laurance et al, J BioGeog, 2002 & Jaimes et al, Appl Geog, 2010 & Li et al, Land Econ, 2012 \\
\hline Agarwal et al, J Agric, Biological, Env Stat, 2002 & Mineots and Polyzos, Forest Policy Econ, 2010 & Arriagada et al, Land Econ, 2012 \\
\hline Southworth et al, Agric, Ecosyst Env, 2004 & Wyman and Stein, Appl Geog, 2010 & Gaveau et al, Cons Lett, 2012 \\
\hline Mertens et al, Int Reg Sci Rev, 2004 & Michalski et al, Global Env Change, 2010 & Htun et al, Env Manag, 2013 \\
\hline Munroe et al, Prof Geogr, 2004 & Ellis et al, Agroforest Syst, 2010 & Wheeler et al, Ecol Econ, 2013 \\
\hline Geoghegan, GeoJ, 2004 & Rueda, Reg Env Change, 2010 & Ferraro et al, Env Res Lett, 2013 \\
\hline Pfaff and Sanchez-Azofeifa, Res Energy Econ, 2004 & Lopez et al, Geog Bulletin, 2010 & Torahi and Rai, J Indian Soc Remote Sens, 2013 \\
\hline Agarwal et al, Ecol Modelling, 2005 & DeFries et al, Nature Geosci, 2010 & Getahun, Forest Ecol Manag, 2013 \\
\hline Zhang et al, Env Mon Assess, 2005 & Trisurat et al, Env Manag, 2010 & Gonga et al, Landscape Urban Planning, 2013 \\
\hline Chowdhury, Appl Geog, 2006 & Kim, T GIS, 2010 & Li et al, Land Use Policy, 2013 \\
\hline Vagen, Agric, Ecosyst Env, 2006 & Soares-Filho et al, Proc Nat Acad Sci, 2010 & Schmitt-Harsh, Appl Geog, 2013 \\
\hline Mena et al, Env Manag, 2006 & Zambrano et al, Cons Soc, 2010 & Qasim et al, Reg Env Change, 2013 \\
\hline Vance and Iovanna, Land Use Policy, 2006 & Armenteras et al, Reg Env Change, 2011 & Patarasuk and Fik, Singapore J Tropical Geog, 2013 \\
\hline
\end{tabular}


Table 3. Summary statistics.

\begin{tabular}{|c|c|c|c|c|c|}
\hline & $\mathrm{n}$ & $\min$ & mean & median & $\max$ \\
\hline Year of publication & 117 & 1,996 & 2,008 & 2,009 & 2,013 \\
\hline Size of study area $\left(\mathrm{km}^{2}\right)$ & 83 & 25 & 443,980 & 15,995 & $9,326,410$ \\
\hline \multicolumn{6}{|l|}{ Data source (multiple allowed) } \\
\hline Aerial photo & 12 & & & & \\
\hline Digital map & 12 & & & & \\
\hline Landsat & 77 & & & & \\
\hline MODIS & 8 & & & & \\
\hline Other $(<30 \mathrm{~m})$ & 9 & & & & \\
\hline Unspecified & 24 & & & & \\
\hline Data resolution (m) & 66 & 1 & 277 & 51 & 1,000 \\
\hline Number of forest cover snapshots & 117 & 1 & 2.7 & 2.0 & 10 \\
\hline Average time interval between forest cover snapshots & 117 & 1 & 7.7 & 7.0 & 40 \\
\hline \multicolumn{6}{|l|}{ Unit of observation } \\
\hline point & 9 & & & & \\
\hline pixel/grid cell & 77 & & & & \\
\hline $\mathrm{parcel} / \mathrm{property}$ & 15 & & & & \\
\hline polygon & 5 & & & & \\
\hline administrative unit & 8 & & & & \\
\hline Size of unit of observation (m) & 72 & 1 & 2,029 & 100 & 25,000 \\
\hline Units of observation sampled? & 78 & & & & \\
\hline Number of observations reported & 79 & 51 & 105,065 & 2,347 & $2,905,337$ \\
\hline Number of regression results reported & 117 & 1 & 4.9 & 3.0 & 46 \\
\hline Number of uniquely named variables & 117 & 1 & 12 & 10 & 44 \\
\hline Number of coefficients & 117 & 2 & 51 & 26 & 452 \\
\hline \multicolumn{6}{|l|}{ Regression functional form (multiple allowed) } \\
\hline Logistic & 53 & & & & \\
\hline Linear or Least Squares & 29 & & & & \\
\hline Probit & 8 & & & & \\
\hline Fixed Effects/Random Effects & 7 & & & & \\
\hline Tobit & 4 & & & & \\
\hline Poisson & 2 & & & & \\
\hline Matching & 4 & & & & \\
\hline Other & 17 & & & & \\
\hline Unspecified & 3 & & & & \\
\hline$R^{\wedge} 2$ (average) & 56 & 0.08 & 0.45 & 0.44 & 0.996 \\
\hline \multicolumn{6}{|l|}{ Reported treatment of spatial autocorrelation (multiple } \\
\hline Sample & 16 & & & & \\
\hline Spatial lag or spatial weighting matrix (W) & 10 & & & & \\
\hline Moran's I or other diagnostic test & 16 & & & & \\
\hline Advanced & 1 & & & & \\
\hline Other & 24 & & & & \\
\hline None or Unspecified & 64 & & & & \\
\hline
\end{tabular}


Table 4. Comparison of findings with previous reviews of drivers of deforestation. Symbol describes association of meta-variable with deforestation ( - : negative association; ? : mixed association, no association, or ambiguous; + : positive association).

\begin{tabular}{|c|c|c|c|c|c|c|}
\hline & $\begin{array}{l}\text { Ferretti-Gallon and Busch, } \\
2014\end{array}$ & $\begin{array}{l}\text { Angelsen and Kaimowitz, } \\
1999\end{array}$ & $\begin{array}{l}\text { Geist and Lambin, } \\
2002\end{array}$ & Rudel, 2009 & $\begin{array}{l}\text { Angelsen and Rudel, } \\
2013\end{array}$ & $\begin{array}{l}\text { Pfaff et al., } \\
2013\end{array}$ \\
\hline $\mathrm{n}$ & 117 & 140 & 152 & 268 & - & - \\
\hline \multicolumn{7}{|l|}{ Biophysical } \\
\hline Elevation & - & & - & - & & \\
\hline Proximity to water & ? & + & & & & \\
\hline Slope & - & & - & - & & \\
\hline Soil suitability & + & + & + & & & \\
\hline Wetness & - & & & & & \\
\hline \multicolumn{7}{|l|}{$\begin{array}{l}\text { Built infrastructure } \\
\quad \text { Proximity to cleared }\end{array}$} \\
\hline land & + & + & + & & & \\
\hline Proximity to roads & + & + & + & + & + & + \\
\hline Proximity to urban area & + & + & + & & & \\
\hline \multicolumn{7}{|l|}{ Agriculture and Timber } \\
\hline Agricultural activity & + & + & + & + & & + \\
\hline $\begin{array}{l}\text { Agricultural price } \\
\text { Proximity to } \\
\text { agriculture }\end{array}$ & + & + & + & & + & \\
\hline Timber activity & $?$ & $?$ & + & + & & + \\
\hline Timber price & $?$ & $?$ & + & & $?$ & \\
\hline \multicolumn{7}{|l|}{ Socioeconomic } \\
\hline Indigenous peoples & - & & & & & \\
\hline Population & + & + & $?$ & + & & \\
\hline Poverty & - & $?$ & + & & & \\
\hline Rural income support & + & & + & & & \\
\hline \multicolumn{7}{|l|}{ Institutional } \\
\hline Community forestry & $?$ & & & & - & \\
\hline Land tenure security & $?$ & $?$ & $?$ & & - & $?$ \\
\hline Protected areas & - & & & - & & - \\
\hline
\end{tabular}


Table 5. Number of studies, forest area, and forest loss (Hansen, 2013) by world region.

\begin{tabular}{|c|c|c|c|c|c|c|}
\hline & $\begin{array}{l}\text { Number of } \\
\text { Studies }\end{array}$ & $\begin{array}{l}\text { Studies }(\% \text { of } \\
\text { total) }\end{array}$ & $\begin{array}{l}\text { Forest Area, } 2000 \\
\left(\mathrm{~km}^{2}\right)\end{array}$ & $\begin{array}{l}\text { Forest Area, } 2000(\% \text { of } \\
\text { total) }\end{array}$ & $\begin{array}{l}\text { Forest Loss } \\
\left(\mathrm{km}^{2}\right)\end{array}$ & $\begin{array}{l}\text { Forest Loss }(\% \text { of } \\
\text { total) }\end{array}$ \\
\hline Central America & 42 & 37.2 & $2,448,780$ & 1.9 & 47,881 & 2.2 \\
\hline Brazil & 15 & 13.3 & $8,384,843$ & 6.5 & 347,516 & 15.9 \\
\hline East Asia & 11 & 9.7 & $13,320,748$ & 10.3 & 209,517 & 9.6 \\
\hline Brazil) & 11 & 9.7 & $9,150,426$ & 7.1 & 183,965 & 8.4 \\
\hline South Asia & 10 & 8.8 & $6,637,233$ & 5.2 & 9,556 & 0.4 \\
\hline East Africa & 8 & 7.1 & $6,191,980$ & 4.8 & 88,806 & 4.1 \\
\hline Southeast Asia & 6 & 5.3 & $2,539,462$ & 2.0 & 106,100 & 4.8 \\
\hline Middle Africa & 3 & 2.7 & $6,510,491$ & 5.1 & 86,665 & 4.0 \\
\hline Caribbean & 2 & 1.8 & 223,331 & 0.2 & 4,296 & 0.2 \\
\hline Eastern Europe & 2 & 1.8 & $17,972,623$ & 14.0 & 360,024 & 16.4 \\
\hline North America & 2 & 1.8 & $17,615,846$ & 13.7 & 514,021 & 23.5 \\
\hline $\begin{array}{l}\text { Southern Europe } \\
\text { Australia New }\end{array}$ & 1 & 0.9 & $1,303,997$ & 1.0 & 15,361 & 0.7 \\
\hline Zealand & 0 & - & $7,939,953$ & 6.2 & 80,498 & 3.7 \\
\hline Central Asia & 0 & - & $3,909,384$ & 3.0 & 961 & 0.0 \\
\hline Melanesia & 0 & - & 496,471 & 0.4 & 6,466 & 0.3 \\
\hline North Africa & 0 & - & $8,237,355$ & 6.4 & 3,080 & 0.1 \\
\hline Northern Europe & 0 & - & $1,648,971$ & 1.3 & 56,701 & 2.6 \\
\hline Southern Africa & 0 & - & $2,665,290$ & 2.1 & 8,077 & 0.4 \\
\hline West Africa & 0 & - & $6,026,348$ & 4.7 & 44,455 & 2.0 \\
\hline West Asia & 0 & - & $4,495,880$ & 3.5 & 3,546 & 0.2 \\
\hline Western Europe & 0 & - & $1,090,573$ & 0.8 & 14,215 & 0.6 \\
\hline TOTAL & 113 & 100 & $128,809,985$ & 100 & $2,191,707$ & 100 \\
\hline
\end{tabular}

